\title{
Business models for the mobile application market from a developer's viewpoint
}

\author{
Frederic Vannieuwenborg, Laurent Mainil, Sofie Verbrugge, Mario Pickavet, Didier Colle
}

Dept. of Information Technology (INTEC)

Ghent University - IBBT

Ghent, Belgium

\{Frederic.Vannieuwenborg, Sofie.Verbrugge, Didier.Colle,

Mario.Pickavet\}@intec.ugent.be, Mainil.Laurent@me.com

\begin{abstract}
Attracted by impressive cash flows and success stories, mobile application developers are trying to penetrate the mobile application market more than ever. Despite this increasing interest, the market configuration is certainly not always clear, let alone how to formulate an optimal business and revenue model from a developer's or provider's viewpoint. Based on case study research, we identified business model characteristics and several revenue models for a mobile application provider. In addition to existing literature on business models, this paper describes two main value network configurations for offering mobile applications: 1) All-in-one mobile application provider, and 2) Outsourcing mobile application provider. Further, we focus on the business model elements of an application developer which can be subdivided in recurrent elements (e.g.: cost structure, key partners, resources, key activities, promotion channels, customer relationships and revenue streams) or unique elements (value proposition and customer segments). This actor specific research allows us to 1) develop a decision chart and 2) to extend existing guidelines in order to determine the most optimal revenue model for a mobile application. The tool and the insights can help new developers to set up their business model or existing mobile application providers to evaluate their current one.
\end{abstract}

Keywords- mobile application market; business model analysis; value network; revenue model

\section{INTRODUCTION}

Due to the more prominent place of smartphones in today's society, mobile applications are gaining more and more importance. At this moment the mobile apps industry represents already a billion-dollar industry and this number will keep on growing. Attracted by these numbers, or just as a hobby, more and more application providers/ developers enter the mobile application market. In order to create a viable business in this immense market landscape, a well thought of

\author{
${ }^{(*)}$ Laurent Mainil worked on this topic in the context of his \\ Master Thesis at the department of Information Technology \\ (INTEC)
}

business model and revenue model are essential for every successful organization, be it a start-up or an incumbent player, now or in the future.

Academic literature, describing the mobile business landscape, its challenges, its opportunities and the roles and actors within it, is available [6] [4] [22]. Other work handles about ontologies for e-business and how to set up and evaluate ebusiness models for doing mobile commerce [20] [11] [14]. But only little work clarifies how to develop a sustainable business and revenue model as an application developer. In the - on application developers focused -research, [4] and [15] present a clear overview of the major actors on the mobile application market. They also focus on the future trends and possible future implications which they counter by proposing some guidelines for application developers. This paper extends this research work with detailed insights in the value network of the mobile application market and how application providers can act in it.

After a short overview of the mobile application market in section II, we explain our research method in Section III while section IV handles about the value networks of the mobile application market. In section $\mathrm{V}$, we focus on just one actor within the total value network namely the application provider. Based on findings, obtained by business and revenue model decompositions, guidelines and a revenue decision chart are provided that should be considered when designing a business model for this actor.

\section{MOBILE APPLICATION MARKET}

Driven by lowered prices, the smartphone market expanded the latest years at very high pace. This, together with the progress in functionality and technical capabilities of the devices (internet access, camera's, music, video, increased processing power, etc.), resulted in the deployment of a market for innovative services and content for the users.

Although the demand for smartphones is a major driver for the growth of the mobile application market [8], the establishment of the structured application market ecosystem in total can be seen as an important driver for the expansion of the mobile application market as well [27]. First application markets were provided by device developers (e.g. Palm), mobile operators, 
etc. But it's only since the launch of Apple's app Store that the real potential of a mobile application market became clear.

Because of its worldwide character, the mobile market represents millions of users. That's the reason why this market is so attractive for application providers. By developing and providing an app that interests even just a little fraction of the total amount of users and by setting the right revenue strategy, chances exist that a valuable business case is created.

Numerous market research reports predict an exponential growth in the number of smartphone users and the resulting mobile data traffic [18] [16] [7]. It can be expected that this substantial growth of demand will result in a growth of the application market as well. So in order to survive in an already nearly saturated market, the need for an appropriate revenue strategy must be emphasized.

\section{METHODOLOGY AND USE CASES}

We conducted this study by deriving the theory from case studies (TABLE I. ). In each case we investigated a successful mobile application provider and his environment. To enforce the validity of the results we strictly followed the eight step process described by Eisenhart [10]: 1) Formulating research questions; 2) Selecting successful Belgian mobile applications; 3) Quantitative and qualitative data collection via interviews, conferences and literature; 4) Leaving room for additional case specific data; 5) Case research and comparing the several cases; 6) Value network investigation and identification of recurrent elements in the business models of mobile applications, which led to development of a framework to choose the optimal business model: 7) Comparison of findings with academic literature; 8) We stop with adding new cases when incremental improvements were marginal.

TABLE I. DESCRIPTION OF THE PRIMARY USE CASES

\begin{tabular}{llcc}
\hline Name & Platform & $\begin{array}{c}\text { Downloads } \\
\text { (April 2011) }\end{array}$ & Description \\
\hline SkiMaps & iOS & 10000 & $\begin{array}{c}\text { Location detection on } \\
\text { a ski slope }\end{array}$ \\
\hline $\begin{array}{l}\text { Swiftkey } \\
\text { Keyboard }\end{array}$ & Android & +100000 & $\begin{array}{c}\text { Typing prediction } \\
\text { and voice recognizing }\end{array}$ \\
\hline Standaard & iOS/ & +25000 & $\begin{array}{c}\text { Online daily journal } \\
\text { Android }\end{array}$ \\
\hline HeatUp! & iOS & +3000 & Memory game \\
\hline $\begin{array}{l}\text { Week } \\
\text { Calendar }\end{array}$ & iOS & +3000000 & $\begin{array}{c}\text { Calendar } \\
\text { synchronization } \\
\text { application }\end{array}$ \\
\hline Quickcopy & Android & +10000 & $\begin{array}{c}\text { Copy easily } \\
\text { frequently used text }\end{array}$ \\
\hline $\begin{array}{l}\text { Shootme } \\
\text { Other secondary use cases were: }\end{array}$ & $\begin{array}{c}\text { Screenshot } \\
\text { application }\end{array}$ \\
\hline $\begin{array}{l}\text { Tap Zoo, High School Hero, Home design } \\
\text { Angry birds, X construction, Whatsapp, MobiGuide QR Code Reader }\end{array}$ \\
\hline
\end{tabular}

To examine and represent the constellation of actors involved in the mobile application market we use a value network. More specifically we define a value network as a network of actors, fulfilling different roles and engaging with each other to create value for the targeted customer.
To get a better view on the different business models we make use of the business model canvas of Osterwalder [21]. Although criticisms indicate the limitations of this model [24] and other more elaborated business model frameworks are available [11] [3], in our study the canvas was a helpful tool. The hands-on canvas is a good starting point for discussions and has a low threshold to involve interviewees. This model elaborates on the four basic segments of a business model; customers, infrastructure, value proposition and financial viability.

After a more generic and abstract explanation of the use of the value network and business model concepts, the cases will be mapped on those developed frameworks. By doing so, several revenue models and recurrent elements of the business models could be identified. Based on that, guidelines to define an optimal business model for a mobile application were formulated as an extension on existing work [15].

\section{VALUE NETWORK FOR MOBILE APPLICATIONS}

To gain insights in the network of interlinked parties, needed to offer a mobile application to customers, a visualization of the complete value network is very helpful. In literature one can find several different definitions of a value network [19] [23] [1] [26] [11] [3]. In this work we formulated a consensus of previous work as follows: a value network is a network of actors, responsible for one or more predefined tasks, which go in a relationship which each other in order to create value. This concept encompasses three key elements: Roles, Actors and Linkages.

\section{A. Roles in the value network}

Roles are tasks in a value network which should be fulfilled in order to create value. Fulfilling a role requires resources (time, money, knowledge, etc.) and induces revenue ((in)direct, (in)tangible). The roles in the mobile application market can be divided in two groups: key roles and non-key roles (indicated in the white boxes in Figure 1.

Key roles are those roles who are always present in the essential and critical path of a successful mobile application. We define following key-roles: concept development, implementation, graphical design, offering support, testing, analysing, promotion of the mobile application, offering of mobile application and application usage.

Non-key roles are more supporting roles, not essential, but value adding: hosting services, $R \& D$, advertising in the mobile application, content aggregation and generation, market optimisation, translation and offering payment services.

Other roles regarding the network transport, hardware devices and regulation aren't discussed in this work because, although they are essential for offering the mobile applications, they aren't included in this conceptualization of the mobile application market. One can see them as back end layers of the mobile application market. 


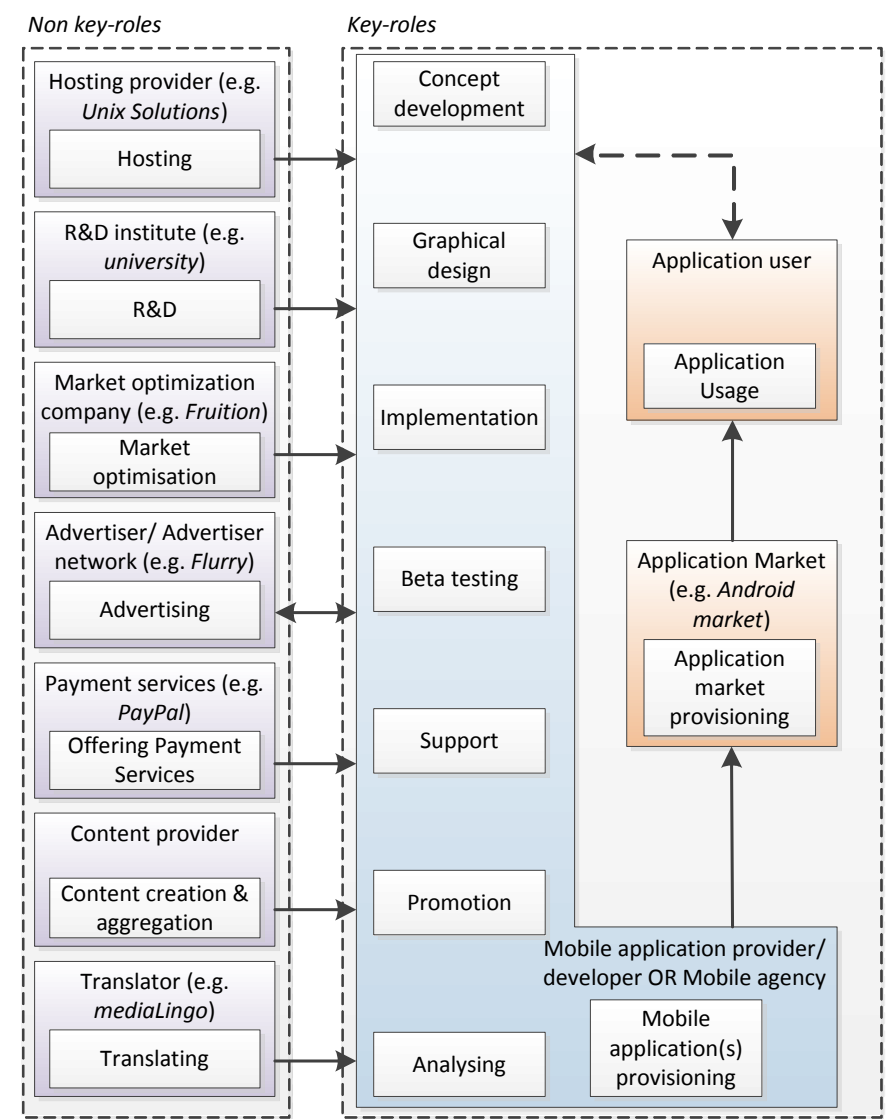

Figure 1. Key and non-key roles in the value network of a mobile market

\section{B. Actors responsible for one or more roles}

TABLE II. gives an overview of all actors involved in the mobile application market.

TABLE II. OVERVIEW OFF DIFFERENT ACTORS IN THE VALUE NETWORK OF A MOBILE APPLICATION MARKET

\begin{tabular}{ll}
\hline \multicolumn{1}{c}{ Actor } & \multicolumn{1}{c}{ Description } \\
\hline $\begin{array}{l}\text { Mobile application } \\
\text { provider }\end{array}$ & $\begin{array}{l}\text { The actor that offers a mobile application to } \\
\text { users }\end{array}$ \\
\hline $\begin{array}{l}\text { Application market } \\
\text { provider }\end{array}$ & $\begin{array}{l}\text { The actor that offers a market place for } \\
\text { application providers to offer their applications }\end{array}$ \\
\hline User & The user of the application \\
\hline $\begin{array}{l}\text { Market optimization } \\
\text { company }\end{array}$ & $\begin{array}{l}\text { Actors who focus on optimizing the different } \\
\text { channels and promotion opportunities in order } \\
\text { to offer a top application }\end{array}$ \\
\hline R\&D institute & Actor who provides (technical) knowledge \\
\hline Hosting provider & $\begin{array}{l}\text { Actor who is responsible for hosting the site or } \\
\text { application }\end{array}$ \\
\hline Translator & This actor translates the application \\
\hline Advertiser & $\begin{array}{l}\text { Actor who wants to put advertisements in the } \\
\text { application }\end{array}$ \\
\hline Content aggregator & Actor who provides content for the application \\
and generator & $\begin{array}{l}\text { This actor offers a service to do electronic } \\
\text { payments }\end{array}$ \\
\hline Payment service & $\begin{array}{l}\text { Actors who develop the mobile application as a } \\
\text { whole in all its facets for other actors }\end{array}$ \\
\hline Mobile agencies &
\end{tabular}

Most prominent actors are: users, application markets, mobile application providers and mobile agencies. In most of the cases these actors together take all key roles for their account. Other actors will often fulfil the non-key roles. Actors are indicated by coloured boxes around roles as can be seen in Figure 1.

As stated before, hardware suppliers and network providers aren't included in our analysis. Though, this does not mean that these actors can't fulfil other roles in the value network (e.g. role of application provider). In addition, there exist some examples of value networks where an additional role is situated between the application provider and the user, namely QoS (quality of service) or access providing. In exchange for an additional fee the network provider can offer higher QoS to the user. In order to recuperate from OTT-applications (Over-theTop) such as Whatsapp, Skype, etc. some network providers block access to these services unless additional fees are paid. National and international discussions about Net Neutrality try to formulate a legal framework to cope with these issues [5].

\section{Value network configurations}

Through our case study research, two main value network configurations were detected when mapping actors onto the different roles.

\section{1) All-in-one mobile application provider}

In this configuration (Figure 2. ) the mobile application provider takes all key roles on his account except providing the application market and application usage. These are respectively the responsibilities of the application markets and the users. The main flow through this configuration starts with the mobile application provider producing the application with some help of actors fulfilling non-key roles. Then he puts the application in the market, from where it gets downloaded by the user. This user in its turn may give feedback and ask for support to the mobile application provider.

For example, we find this configuration in the SkiMaps iPhone application (Figure 2. ). This application makes it possible to localize yourself in a ski resort. In this case, the mobile application provider is supported by a hosting provider (providing server space) and the ski resorts (providing the trail maps). The application market is the Apple App Store and the users are iPhone users.

Other use case applications that follow this configuration: QuickCopy, HeatUp!HD, Swiftkey keyboard>

\section{2) Outsourcing mobile application provider}

This configuration (Figure 3. ) differs from the previous one because in this case the mobile agency takes over some roles from the mobile application provider. The mobile agency now produces the application for the mobile application provider, which puts it onto the market.

For example, we find this configuration in the Standaard application (Figure 3. ). In this application a publisher offers a digital version of a newspaper. The mobile application provider is in this case the publisher (Corelio). Due to a lack of expertise they outsource the production of the application to a mobile agency (Mobile Web). The supporting actors of the mobile application provider are in this case advertisers. The 
application is offered to iPad and Android tablet users through the Apple App Store and Google Android Market.

Another example of this configuration is: Maes.be a mobile application developed by Plane Tree Software commissioned by a Belgian brewery.

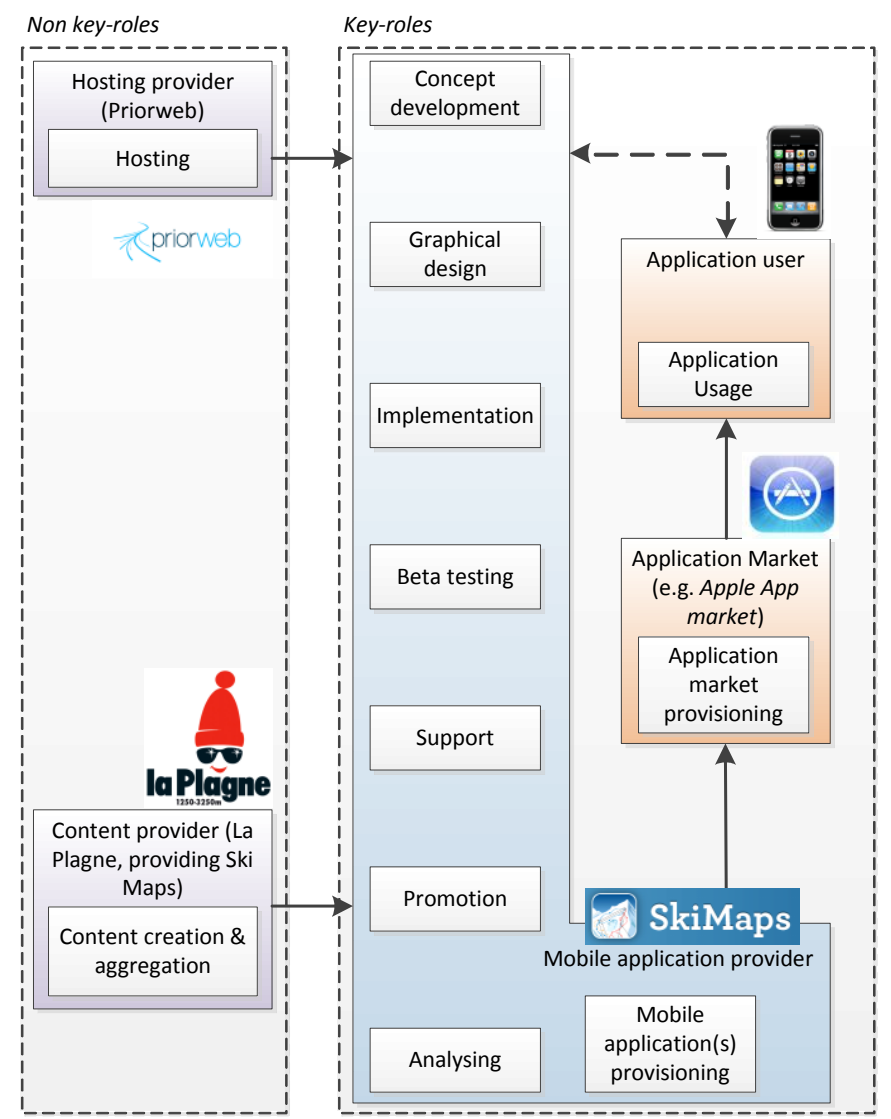

Figure 2. All-in-one mobile application provider

The all-in-one mobile application provider is a value network often adopted by hobbyists and professional application developing entrepreneurs. The outsourcing mobile application provider model is frequently used when firms want to offer an application to its customers but without having the right capabilities to develop the app themselves. Next to these two main configurations, other possible variations in the mobile market value network are:

- Mobile agencies outsourcing the development of the application to low-income countries. MobiGuide $Q R$ Code Reader is an application to read QR codes. It's provided by Mobinest Srl [17], but the application is developed by IADI application programmers .

- Mobile agencies internalizing non-key roles such as hosting, translating and advertising.

- Mobile application providers outsourcing every key or non-key role to experts, except the role of content provider. (Cases; Shootme \& Week calendar, outsourcing the graphical design)

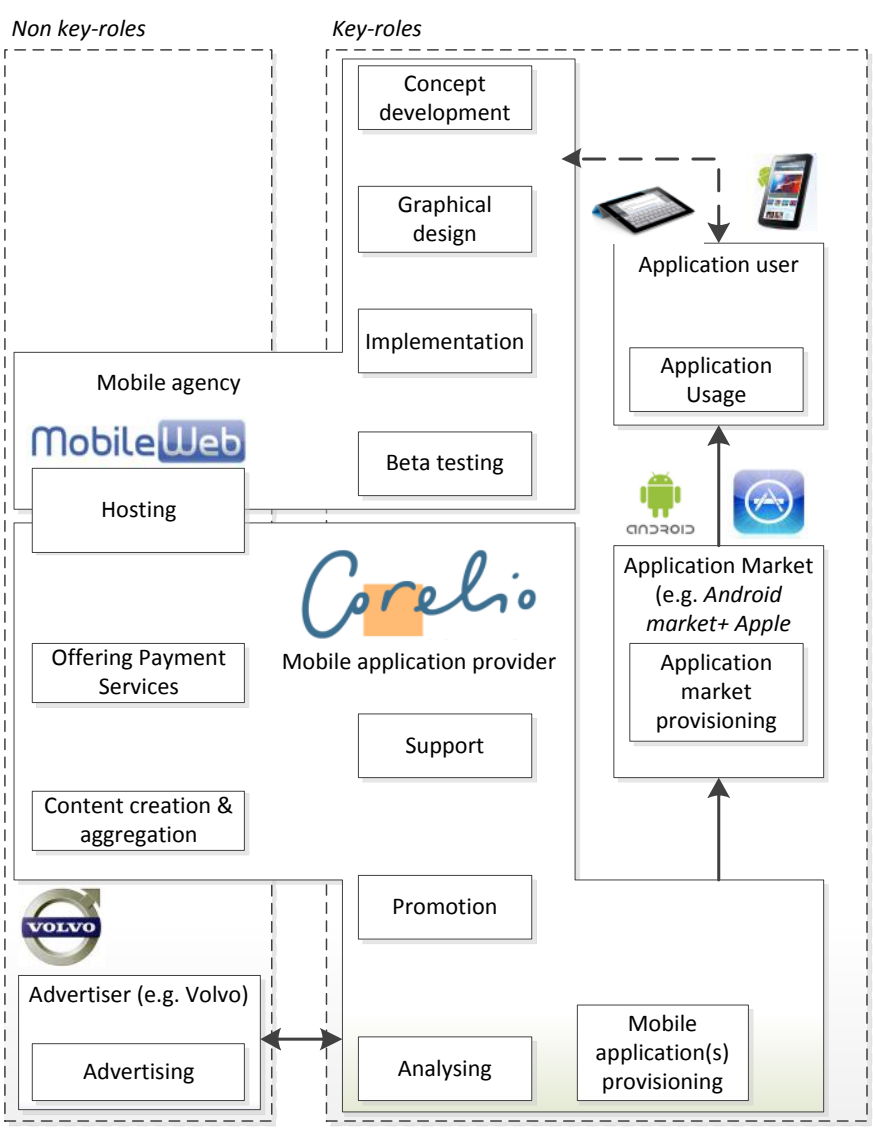

Figure 3. Outsourcing mobile application provider

\section{BUSINESS MODELS FOR MOBILE APPLICATION PROVIDERS}

In the previous chapter, we investigated the value network of a mobile application market. Now, within this value network, we will isolate a single application provider in order to dive into the business model of this actor. Contrary to existing literature [3] we see a business model as a firmindividual fact that is an element from a surrounding network. That surrounding network describes how actors and their individual business models interact. Since the roles and tasks that an actor should fulfil are inherently a part of the business model, we state that a value network represents the surrounding environment where actors with their individual business model do fit in.

By using a business model canvas [21] we identify most recurring business elements in offering a mobile application. Next to that, guidelines extensions and a flowchart are developed to help application providers choose for a revenue model.

\section{A. Business model elements}

Since there is already a lot of literature available on the definition and usage of a business model [28] [25] [3] [4] [9], we will not formulate an own interpretation. Because of the quality of the canvas as discussion tool and its well described building blocks, (Figure 4. ), we chose to use a definition 
formulated by [21], which is: "A business model describes the rationale of how an organization creates, delivers, and captures value",

In their work, the authors identified nine building blocks (TABLE III. ) that cover the four most important business elements: Customers, Infrastructure, Value proposition and Financial viability.

TABLE III. NiNE BUILDING BLOCKS OF A BUSINESS MODEL (SOURCE: [21] )

\begin{tabular}{|c|c|c|}
\hline $\begin{array}{l}\text { Business } \\
\text { elements }\end{array}$ & $\begin{array}{l}\text { Building } \\
\text { Block }\end{array}$ & Description \\
\hline 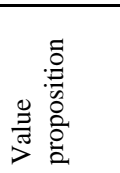 & $\begin{array}{l}\text { Value } \\
\text { proposition }\end{array}$ & $\begin{array}{l}\text { The value proposition of what is offered to the } \\
\text { market }\end{array}$ \\
\hline \multirow{2}{*}{ 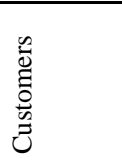 } & $\begin{array}{l}\text { Customer } \\
\text { segments }\end{array}$ & $\begin{array}{l}\text { The segment(s) of clients that are addressed } \\
\text { by the value proposition }\end{array}$ \\
\hline & $\begin{array}{l}\text { Customer } \\
\text { relationships }\end{array}$ & The relationships established with clients \\
\hline \multirow{4}{*}{ 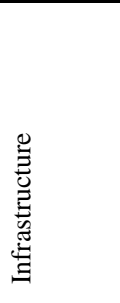 } & Channels & $\begin{array}{l}\text { The communication and distribution channels } \\
\text { to reach clients and offer them the } \\
\text { value proposition }\end{array}$ \\
\hline & $\begin{array}{l}\text { Key } \\
\text { activities }\end{array}$ & $\begin{array}{l}\text { The key activities necessary to implement the } \\
\text { business model }\end{array}$ \\
\hline & $\begin{array}{l}\text { Key } \\
\text { resources }\end{array}$ & $\begin{array}{l}\text { The key resources needed to make the } \\
\text { business model possible }\end{array}$ \\
\hline & Key partners & $\begin{array}{l}\text { The key partners and their motivations to } \\
\text { participate in the business model }\end{array}$ \\
\hline \multirow{2}{*}{ 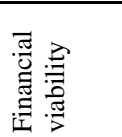 } & $\begin{array}{l}\text { Cost } \\
\text { structure }\end{array}$ & $\begin{array}{l}\text { The cost structure resulting from the business } \\
\text { model }\end{array}$ \\
\hline & $\begin{array}{l}\text { Revenue } \\
\text { stream }\end{array}$ & $\begin{array}{l}\text { The revenue streams generated by the } \\
\text { business model }\end{array}$ \\
\hline
\end{tabular}

Each mobile application is characterized by a specific value proposition for a specific customer segment within the total market of smartphone users. Each application is offered for a sort of revenue stream (an application offered for free has a revenue model as well, but it is a zero transaction). We define following business model building blocks as application dependent, and thus, unique elements:

- The value proposition is supposed to be unique, but it's possible to formulate general application categories. Examples of such categories are: games, navigation, health, productivity, etc.

- The targeted customers can be all smartphone users in general, or it can be a small niche of this group, e.g. smartphone users who are skiers as well (SkiMaps).

Next to these unique characteristics of each case, we could detect, by use cases research, following recurrent elements in the business models of mobile applications.

- Key partners: application market (Android market, Apple App market), hosting providers,

- Key activities: development and support provisioning for the application

- Key resources: the developed application itself
- Customer relationships: personal assistance through feedback loops and personal support

- Channels: blogs, websites, twitter, facebook, etc. as promotion channels. Application markets for the distribution of the application. And support and feedback communication often happens via e-mail.

- Cost structure: fee for application market entrance, $30 \%$ of the application sale revenues for the application market provider, developing time, wages, cost for IT-devices and cost for hosting.

- Revenue streams: in next paragraph, several revenue models are discussed.

Figure 4. presents the business model canvas for the Skimaps application.

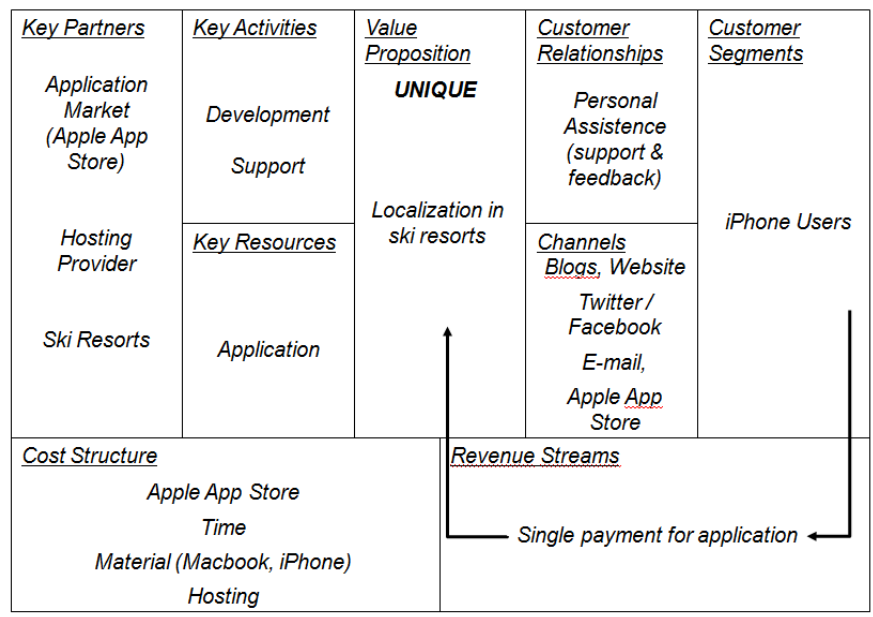

Figure 4. Business model canvas of the mobile application Market

\section{B. Revenue models}

After clarifying the value network where an application provider is positioned in, we further investigate its business model and more specific the revenue building block. By doing so, we want to elucidate how an application provider can make money in a very competitive market.

When classifying the use cases, several revenue models can be distinguished that can be applied by an application provider. Homogenous models are basic models; heterogeneous models on the other hand are mixtures of different homogeneous revenue models.

Homogenous models are:

- Application purchase model: a onetime payment allows you unlimited use of the application. Examples of the app purchase model are: SkiMaps, Heat Up! HD, Week Calendar

- In-app purchase model: The application usage itself is free, but when a customer wants extra features (eg. new levels of a game, new options of the application, etc.) he/she can buy it within the application. According to [2] reasons for the success of this model 
are the fact that users that buy extra features are very dedicated to the application and therefore somewhat less price sensitive. Also expectations are known before the purchase, so risk for disappointments is smaller and customer satisfaction higher. Having the opportunity to accelerate the progress of the game seems to be a success in these times of rush and impatience. An example of the in-app purchase model is: Tap Zoo, a game to build your own zoo (TOP 50 iPhone application)

- Advertising model: The application is freely available for the users, revenues are provided by advertisers who place advertisements in the application. In general, this revenue model is not seen as highly profitable and on top of that, advertisements can create a barrier for users. An example of the advertising model is: High School Hero, an iPhone application with an effective cost per mille (eCPM; cost for advertising per 1000 users) of $\$ 68$ [13].

- Freemium model: In this revenue model we distinguish two user types: free users and premium users. Free users have access to a free edition of the application with limited functionality and potential presence of advertisements. Free users that are positive about the free edition can opt to buy a full or ad-free version of the application. In the mobile gaming category, the freemium revenue model is the leading model according to [29]. An example of the freemium model is: Home Design 3D. In the free version, a user can't save his design.

- $\quad$ Free model: Application usage for free. It's clear that no direct revenues can result from this model. Often, developer hobbyists use this model or actors who want to generate indirect revenues through the development of an application. For example Instagram, the photoapplication which was bought for $\$ 1$ billion by Facebook.

- Subscription model: Users pay a time-based fee to use the application. Because subscription fees are not very attractive for most users, an application provider has to have a very strong value proposition when using this revenue model. An example of this model is: Showpad. This application allows users to compose an advanced catalogue that they can show to their customers. The value proposition of this application is strong enough to ask $€ 49 /$ month.

- Donation model: The application is offered for free, users can donate an undefined amount of money to the application developer. It can be expected that almost no revenues can result from this model without offering a huge added value to the users.
Heterogeneous models are for example:

- App purchase model/ in-app purchase model: Onetime fee + payments for extra features. Angry Birds is an example of this model.

- $\quad$ Freemium/ advertising model: Free application usage with advertising, without advertising when you pay for it. Example: $X$ Construction.

- Publisher model: App/in-app purchase or subscription fee for the users. + revenues from advertisers. Example: Standaard application.

How to generate a revenue stream from offering mobile applications is partially dependent of the value proposition. By mapping the value propositions on the several identified revenue models, we defined direct linkages. Following flowchart, based on the linkages between value proposition and revenue model, provides a possible selection tool to decide which revenue model you should take.

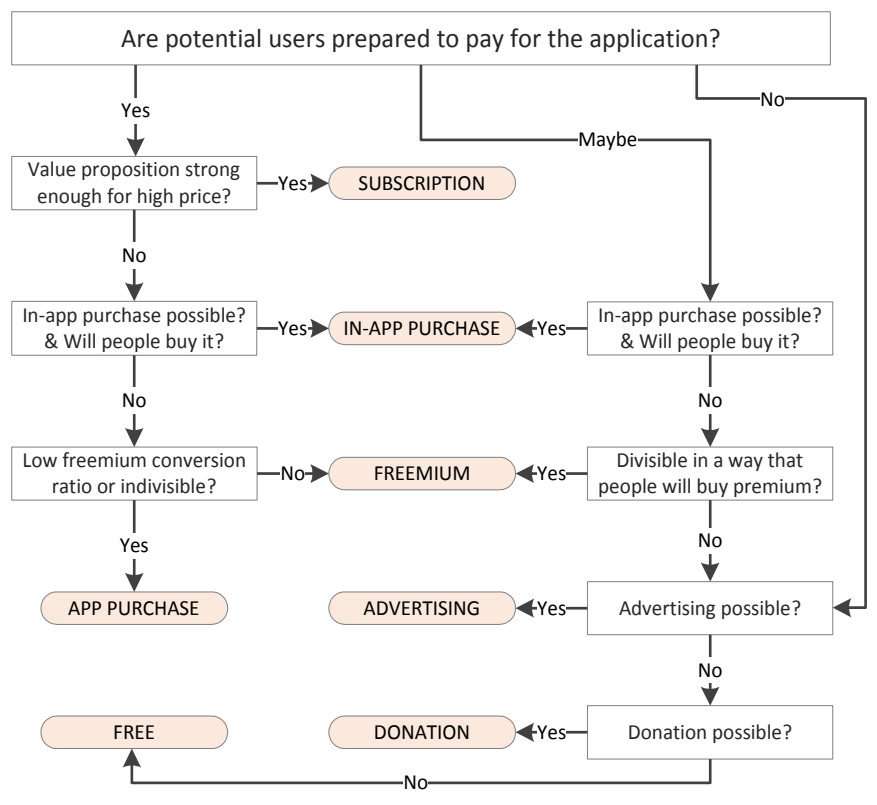

Figure 5. Flowchart for revenue model selection

\section{GUIDELINES}

After describing the value network of the mobile application market and identifying the key recurring elements and revenue models of the business model of an application provider, we want to extend existing guidelines [15] for application providers/ developers. Based on our case study research we gained insights that could help new application providers/ developers to set up their business model or existing mobile application providers to evaluate their current one. Most important guidelines are:

1) Choose for iPhone applications to make profits iPhone applications are on average more lucrative than Android applications. According to [12], on average a same app can generate about four times more revenue when provided via iOS instead of the Android market. Profit focused mobile 
application providers should therefore produce initially iPhone applications and only in a second stage making the application available on Android as well.

\section{2) Create a strong value proposition}

The value proposition is the core of the business model. Without the capability to offer a strong value proposition, the application can never win in an already very competitive market.

\section{3) Keep costs low}

Cost structures of mobile application providers are often similar (Figure 4. ) Take every component into account and try to minimize it. For example: look for cheap hosting actors; try to recycle your code; do not buy the most powerful computers or test devices; find a trade off between quality of the application (time consuming) and the cost for development; provide customers support in a nearly fully automated way, (standard mails, frequently asked questions - section (FAQ)).

\section{4) Take care of your customers}

Take care of your customers by providing dedicated and quick support, feedback and updates.

\section{5) Promote your application}

The most effective way to promote your application is getting featured in application markets or blogs. Other good methods are having a website or twitter and attending conferences. Do always concentrate your efforts. Try to do it as simultaneous as possible. This cumulated effect will have a bigger impact on the rankings.

\section{6) Choose the right revenue model}

Without a well thought of revenue model, it can be very hard to generate revenues by developing and providing an application. Based on the findings in this work, we propose a simple decision chart (Figure 5. ) to figure out what the most appropriate revenue model for your application could be.

Other useful additions are:

- Always try to combine the freemium model with the advertising model. In that case, you express clearly the benefits of paying for an application.

- When using the in-app revenue model, check whereas the app purchase model isn't possible at the same time as well.

- Avoid showing advertisements when customers paid for the mobile application.

- Avoid using the app purchase revenue model when users already have to pay for the content. (Except when the value proposition is strong enough like a journal publisher.)

- Applications with low user friendliness are a key to failure.

\section{CONCLUSIONS}

To gain insights in the market where an application developer or provider is situated in, a value network was created that reveals all actors involved and the roles they should fulfil. We defined following key roles needed to offer a mobile application: application concept development, implementation, graphical design, offering support, testing and promotion of the mobile application, providing the mobile application, providing the mobile application market and mobile application usage itself. Supporting roles were called non-key roles and typically compass: hosting services, $R \& D$, advertising in the mobile application, content aggregation and generation, translation of the application, market optimisation and payment services.

Most important actors in the mobile application landscape are: the user, application developer/provider, application market, hosting provider, advertisers, market optimisation companies, research departments, mobile agencies, translators and payment service providers.

Most frequently identified value network configurations are: the all-in one mobile application provider configuration, whereby the application provider is responsible for practically any role and the outsourcing mobile application provider configuration were roles are outsourced to mobile agencies.

Within this network of different actors we focused on the business models of mobile application providers. In several building blocks of the business model, recurrent elements could be detected. Key partners of an application developer are often the application market and hosting providers. Application development and support provisioning are typical key activities, while the developed mobile application itself is the key resource. In the cost structure, recurrent elements are the cost for hosting, the cost for application market entrance, costs for IT-devices and for developing the application. Other recurrent elements can be found in the channel and customer relationship building blocks of the business model. Because mostly, customers are reached via blogs, websites, social media channels, e-mail and the application markets themselves. Customer relationships are often based on feedback and solid support. The revenue streams can be divided in subcategories. In contrast with the recurrent elements of a business model for mobile applications, unique elements are typical the value proposition and the targeted customers.

Next to the basic homogenous revenue models (application purchase model, in-app purchase mode, advertising model, freemium mode, free model, subscription model and donation model) heterogeneous mixtures of revenue models were detected as well (app purchase model/ in-app purchase model, freemium/ advertising model, publisher model).

Based on theoretically valid findings, six guidelines for business model optimization for mobile application providers were formulated as an extension on previous research work.

In addition a decision process chart is developed to help selecting the most appropriate revenue model for the application.

\section{FUTURE WORK}

Further research on the impact of different business model elements on venture capitalists would be very interesting. By doing so, we could extend the existing guidelines with 
additional info on how to optimize the business model of a mobile application provider in order to gain interests of funding sources.

Defining and quantifying the relationship between the revenue model and the profitability of a mobile application would be a valuable extension on this work.

\section{ACKNOWLEDGMENT}

This research work was partially supported by the Concerted Research Actions grant for the research project: "High Potential Entrepreneurship and entrepreneurial value creation: context influences, context interactions and context extension" (project code 01G03011) from the Ghent University. It also received support from the NBB, National Bank Belgium.

\section{REFERENCES}

[1] V. Allee, "Value network analysis and value conversion of tangible and intangible assets," Journal of Intellectual Capital, vol. 9, pp. 5-24, 2008.

[2] C. Anderson, Free: The Future of a Radical Price: Hyperion, 2009.

[3] P. Ballon, "Business modelling revisited: the configuration of control and value," info, vol. 9, pp. 6-19, 2007.

[4] H. Bouwman, H. De Vos, and T. Haaker, Mobile service innovation and business models: Springer Verlag, 2008.

[5] M. Broersma. (2012). Netherlands Institutes Net Neutrality Law. Available:

http://www.techweekeurope.co.uk/news/netherlands-netneutrality-77539

[6] G. Camponovo and Y. Pigneur, "Analyzing the mbusiness landscape," Annals of telecommunications, vol. 58, pp. 59-77, 2003.

[7] Cisco, "Cisco Visual Networking Index: Global Mobile Data Traffic Forecast Update, 2011-2016," Cisco2012.

[8] M. N. Cortimiglia, A. Ghezzi, and F. Renga, "Mobile Applications and Their Delivery Platforms," IT Professional, vol. 13, pp. 51-56, 2011.

[9] M. De Reuver and T. Haaker, "Designing viable business models for context-aware mobile services," Telematics and Informatics, vol. 26, pp. 240-248, 2009.

[10] K. M. Eisenhardt, "Building Theories from Case Study Research," The Academy of Management Review, vol. 14, pp. 532-550, 1989.

[11] E. Faber, P. Ballon, H. Bouwman, T. Haaker, O. Rietkerk, and M. Steen, "Designing business models for mobile ICT services," 2003.

[12] Flurry. (2011, 15/04/2012). App Developers Bet on iOS over Android this Holiday Season. Available: http://blog.flurry.com/bid/79061/App-Developers-Beton-iOS-over-Android-this-Holiday-Season

[13] Flurry. (2012). AppCircle Rewards Success Story: High SchoolHero generates eCPMs exceeding \$60. Available: http://venturebeat.com/2010/08/25/flurrys-appcirclerewards-generates/
[14] J. Gordijn, H. Akkermans, and J. Van Vliet, "Designing and evaluating e-business models," IEEE Intelligent Systems, vol. 16, pp. 11-17, 2001.

[15] A. Holzer and J. Ondrus, "Mobile application market: A developer's perspective," Telematics and Informatics, vol. 28, pp. 22-31, 2011.

[16] W. Lam. (2012, 15/04/2012). Lumia 900 Introduction to Trigger Smartphone Renaissance for Nokia and Microsoft IHS iSuppli Mobile Wireless Communications Service. Available: http://www.isuppli.com/Mobile-andWireless-Communications/News/Pages/Lumia-900Introduction-to-Trigger-Smartphone-Renaissance-forNokia-and-Microsoft.aspx

[17] S. Mobinest. (2012, 15/04/2012). Contact form for QRlinQ. Available: http://www.qrlinq.com/contact.html

[18] Nielsen. (2012, 15/04/2012). Smartphones Account for Half of all Mobile Phones, Dominate New Phone Purchases in the US. Available:

http://blog.nielsen.com/nielsenwire/online mobile/smart phones-account-for-half-of-all-mobile-phones-dominatenew-phone-purchases-in-the-us/

[19] R. Normann and R. Ramirez, Designing interactive strategy: From value chain to value constellation: Wiley Chichester, 1998.

[20] A. Osterwalder and Y. Pigneur, "An e-business model ontology for modeling e-business," 2002, pp. 17-19.

[21] A. Osterwalder, Y. Pigneur, and T. Clark, Business Model Generation: A Handbook for Visionaries, Game Changers, and Challengers: John Wiley \& Sons, 2010.

[22] J. Paavilainen, Mobile business strategies: understanding the technologies and opportunities: Addison-Wesley, 2002.

[23] J. Peppard and A. Rylander, "From Value Chain to Value Network::: Insights for Mobile Operators," European Management Journal, vol. 24, pp. 128-141, 2006.

[24] A. Rosenberg, M. von Rosing, G. Chase, R. Omar, and J. Taylor, "Applying Real-World BPM in an SAP Environment," 2011.

[25] S. M. Shafer, H. J. Smith, and J. C. Linder, "The power of business models," Business horizons, vol. 48, pp. 199207, 2005.

[26] C. B. Stabell and Ø. D. Fjeldstad, "Configuring value for competitive advantage: on chains, shops, and networks," Strategic management journal, vol. 19, pp. 413-437, 1998.

[27] M. Stanley. (2012, 15/04/2012). Observing the Mobile Application Evolution. Available: http://www.mobileworldmag.com/observing-the-mobileapplication-evolution.html

[28] D. J. Teece, "Business models, business strategy and innovation," Long Range Planning, vol. 43, pp. 172-194, 2010.

[29] J. Valadares. (2011, 15/04/2012). Free-to-play Revenue Overtakes Premium Revenue in the App Store. Flurry. Available: http://blog.flurry.com/bid/65656/Free-to-playRevenue-Overtakes-Premium-Revenue-in-the-App-Store 